\title{
Ellipsometry of hydrous platinum oxide layers and electrodispersed platinum surfaces resulting from their electroreduction
}

\author{
J. O. Zerbino, C. Perdriel and A. J. Arvia \\ Instituto de Investigaciones Fisicoquímicas Teóricas y Aplicadas, Facultad de Ciencias Exactas, Universidad Nacional de La Plata, \\ Casilla de Correo 16, Sucursal 4, (1900) La Plata (Argentina)
}

(Received January 7, 1993; accepted March 9, 1993)

\begin{abstract}
The ellipsometric characteristics of relatively thick hydrous Pt oxide layers (HPtOLs) produced by oxidationreduction cycling in the $0-2.4 \mathrm{~V}$ range in $1 \mathrm{M} \mathrm{H}_{2} \mathrm{SO}_{4}$, and the surface topography of electrodispersed $\mathrm{Pt}$ electrodes (EDPtEs) obtained by electroreducing the HPtOLs have been determined in the $400-700 \mathrm{~nm}$ range at $25^{\circ} \mathrm{C}$. The HPtOL is light absorbing and can be described as a layer made up of $\mathrm{H}_{2} \mathrm{O}$ and $\mathrm{Pt}$ oxide. The water content increases with increasing layer thickness, approaching a $\mathrm{PtO}_{2}-\mathrm{to}-\mathrm{H}_{2} \mathrm{O}$ molar ratio of about 4 . The EDPtE resulting from the slow electroreduction of HPtOL can be described as a rough structure with a metal-to-void ratio close to 0.5 , which is consistent with a brush-like geometry.
\end{abstract}

\section{Introduction}

Electrodispersed Pt electrodes (EDPtEs) with a definite roughness can be obtained by electroreducing hydrous Pt oxide layers (HPtOLs) which have been formed on $\mathrm{Pt}$ electrodes by application of a fast periodic perturbing potential $[1,2]$. The structure of the HPtOL consists of an inner compact PtO layer [1,3-6], and an outer layer which has been formulated as $\left[\mathrm{PtO}_{2}(\mathrm{OH})_{2}\right.$ $\left.\left(\mathrm{H}_{2} \mathrm{O}\right)_{2}\right]^{2-}$ or $\left[\mathrm{Pt}(\mathrm{OH})_{6}\right]^{2-}[3]$. The optical growth of the outer layer in acid takes place at about $2.3 \mathrm{~V}$ with respect to a reversible hydrogen electrode $[7,8]$. $\mathrm{Pt}($ IV) species are present in the thick oxide layer structure formed at relatively high positive potentials [9-13].

The topography of the EDPtE was described as a brush-like topography made up of round capped cylindrical bristles [14-17]. The present work is devoted to investigating the ellipsometric response of HPtOLs and EDPtEs to obtain information about the water-toplatinum oxide and metal-to-void ratios, respectively, and their variation with environmental conditions.

\section{Experimental details}

The ellipsometer was a Rudolph Research type 437002-200 E instrument equipped with a $150 \mathrm{~W}$ tungsten lamp and an RCA IP 21 photomultiplier. It was employed in the null mode with the incident light beam at $69^{\circ}$ and the azimuth angle (compensator) set at $135^{\circ}$. The $400-700 \mathrm{~nm}$ spectral range was covered by using adequate filters. Measurements of the phase shift $\Delta$ and the arctangent $\Psi$ of the amplitude ratio of the orthogo- nal components of the polarized light, were carried out at $25^{\circ} \mathrm{C}$.

The cell consisted of two optical glass windows $(\phi=20 \mathrm{~mm})$ for the reflection of the light beam at the Pt working electrode surface (apparent area, $1.13 \mathrm{~cm}^{2}$ ), the latter being horizontally placed. A Pt counterelectrode and a hydrogen reference electrode were employed. $1 \mathrm{M} \mathrm{H}_{2} \mathrm{SO}_{4}$ was used. The alignment of the cell with respect to the incidence plane allowed readings to be made at different locations of the electrode surface (light beam section, $0.7 \mathrm{~mm}$ ).

The working electrode after providing a well-behaved voltammogram was held at $0.06 \mathrm{~V}$ to obtain the ellipsometric parameters of the blank. Subsequently, the potential was stepped to $1.52 \mathrm{~V}$ to find the ellipsometric parameters of the O-adatom-coated Pt electrode. Then it was subjected to a $3.3 \mathrm{kHz}$ square wave potential between 0.00 and $2.40 \mathrm{~V}$ for $10 \mathrm{~s}<t<240 \mathrm{~s}$ to accumulate the HPtOL [1]. The ellipsometric parameters of the HPtOL were determined at $1.52 \mathrm{~V}$. Subsequently, the HPtOL was electroreduced at either 0.002 or $0.1 \mathrm{~V} \mathrm{~s}^{-1}$, and the electroreduction charge $Q_{\mathrm{R}}$ was evaluated. Finally, the optical parameters of the EDPtE were determined.

The roughnesses of EDPtEs were determined through the voltammetric $\mathrm{H}$-atom electrodesorption charge, the $\mathrm{H}$ adatom monolayer charge density being taken as $0.210 \mathrm{mC} \mathrm{cm}^{-2}$. The relative increase $R$ in the electrode surface area (hereafter called the roughness factor) was evaluated from the following ratio:

$R=\frac{A_{\mathrm{R}}}{A_{\mathrm{G}}}$ 
where $A_{\mathrm{R}}$ is the real surface area of the EDPtEs and $A_{\mathrm{G}}$ is the geometric surface area of a standard smooth $\mathrm{Pt}$ electrode.

The accuracy and reproducibility of results were determined considering the known sources of uncertainty which are described in the literature [18-20]. The absolute uncertainties in the polarizer and analyser readings were about $\pm 0.2^{\circ}$. This value represents our estimate of the $95 \%$ confidence interval. The reproducibility of these readings appears to be of the order of $0.02^{\circ}$ when examining the same spot and when taking measurements by the same sequence of the polarizer and analyser. Large variations in readings were found when scanning over some of the surfaces and these are ascribed to the variable nature of the surface texture.

\section{Results}

\subsection{Fitting procedure}

Ellipsometric data were obtained at $405,450,492$, 546,580 and $671 \mathrm{~nm}$. The starting fitting procedure assumed HPtOL and EDPtE to be a single isotropic homogeneous layer. Data obtained in this way were compared with the results for single uniaxial anisotropic films [21]. The program used a subroutine DFMCG to find the local minimum of a function of several variables by the method of conjugated gradients. For each wavelength $\lambda_{i}$, the experimental values $\Delta^{i j}$ and $\Psi^{i j}$ corresponding to a different film thicknesses $d_{j}$ were fitted by a single pair of optical indices $n_{i}$ and $k_{i}$. Simultaneously, for each value of $d_{j}$, the optical data measured at different $\lambda_{i}$ must fit the same real $d_{j}$ value. Accordingly, the optical constants were unambiguously calculated by minimizing the function $F$ :

$F=\sum_{j=1}^{27} \sum_{i=1}^{6}\left(\Delta_{\exp }^{i j}-\Delta_{\text {theor }}{ }^{i j}\right)^{2}+\left(\Psi_{\exp }^{i j}-\Psi_{\text {theor }}{ }^{i j}\right)^{2}$

where the $i$ stand for the different $\lambda_{i}$, and the $j$ denote different values of $d_{j}[18]$.

\subsection{The hydrous Pt oxide layers}

The values of $\Delta$ and $\Psi$ for the HPtOLs measured at $1.52 \mathrm{~V}$ in the central part of the electrode are shown in Fig. 1. The values of $n$ and $k$ and their dependences on $\lambda$ (Fig. 2) are consistent with an HPtOL containing a relatively large amount of water. The calculated values of the HPtOL thickness $d_{\text {ox }}$, at different positions on the same electrode show a radial distribution of $d_{\text {ox }}$ on the surface which can be related to the non-uniform primary current distribution at the $\mathrm{Pt}$ disc electrode [22].

\subsection{Ellipsometric data of electrodispersed Pt electrodes}

Figures 3(a) and 3(b) show the radial distribution of ellipsometric data for the same EDPtE at $v=$

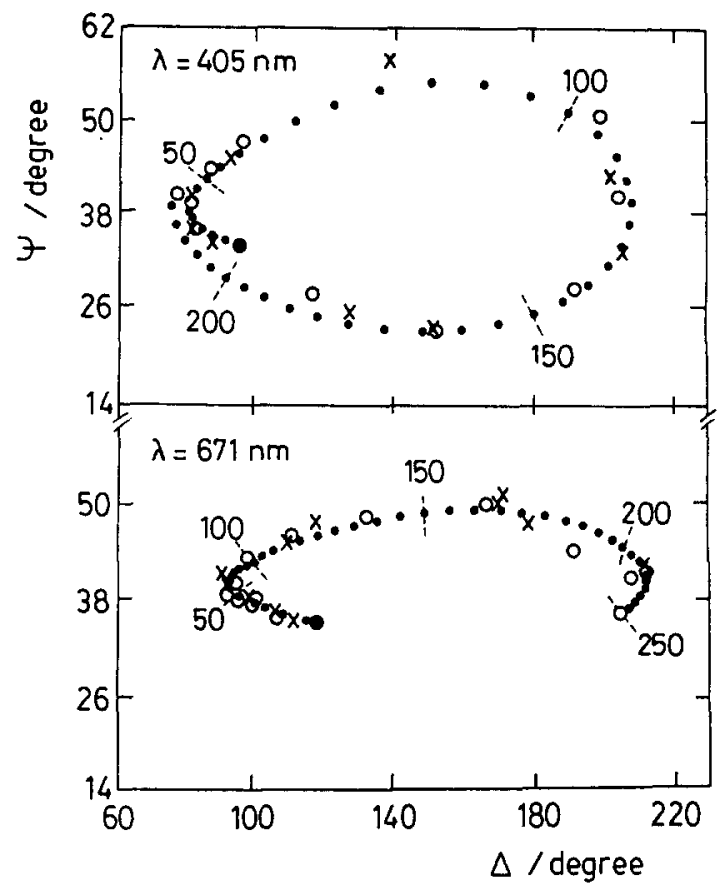

Fig. 1. $\Delta$ vs. $\Psi$ plots for HPtOLs at six wavelengths. The $\mathrm{Pt}$ oxide layers were electroreduced at two scan rates, namely $0.002 \mathrm{~V} \mathrm{~s}^{-1}(x)$ and $0.1 \mathrm{Vs}^{-1}(O)$ where a $\mathrm{Pt}$ base is used for the scan rate of $0.1 \mathrm{~V} \mathrm{~s}^{-1}:-, \Delta v s . \Psi$ plots calculated with $n$ and $k$ values taken from Fig. 2. The numbers indicate the film thickness in nanometres.

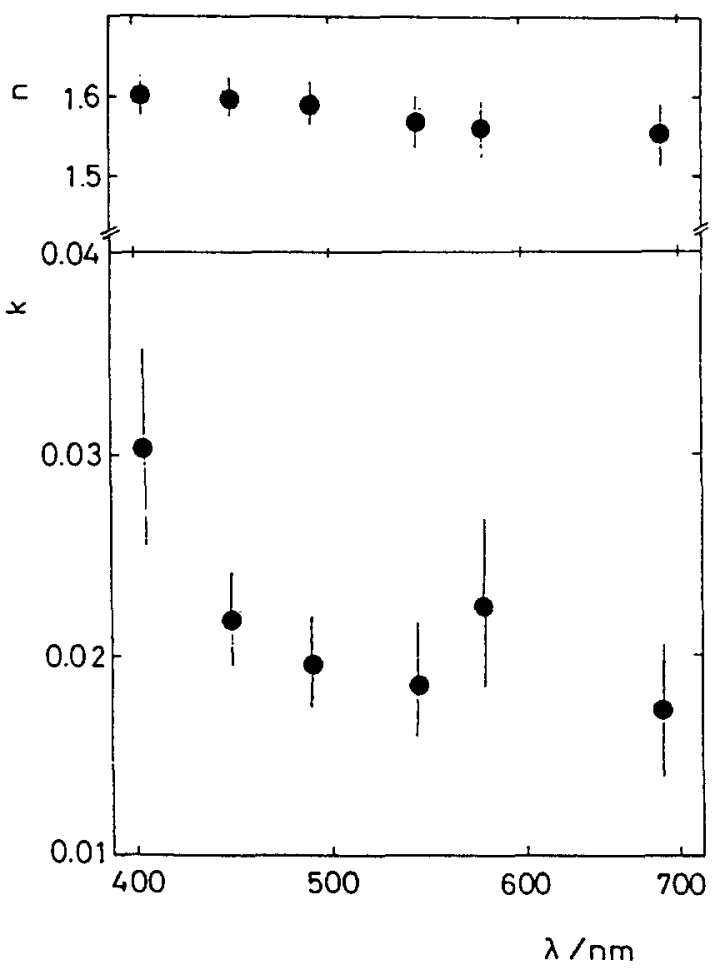

Fig. 2. $n$ vs. $\lambda$ and $k$ vs. $\lambda$ plots for HPtOLs at $1.52 \mathrm{~V}$.

$0.002 \mathrm{~V} \mathrm{~s}^{-1}$, and the effect of $v$ for different EDPtEs respectively. Despite data scattering, there is a clear dependence of the ellipsometric parameters on $v$. The 


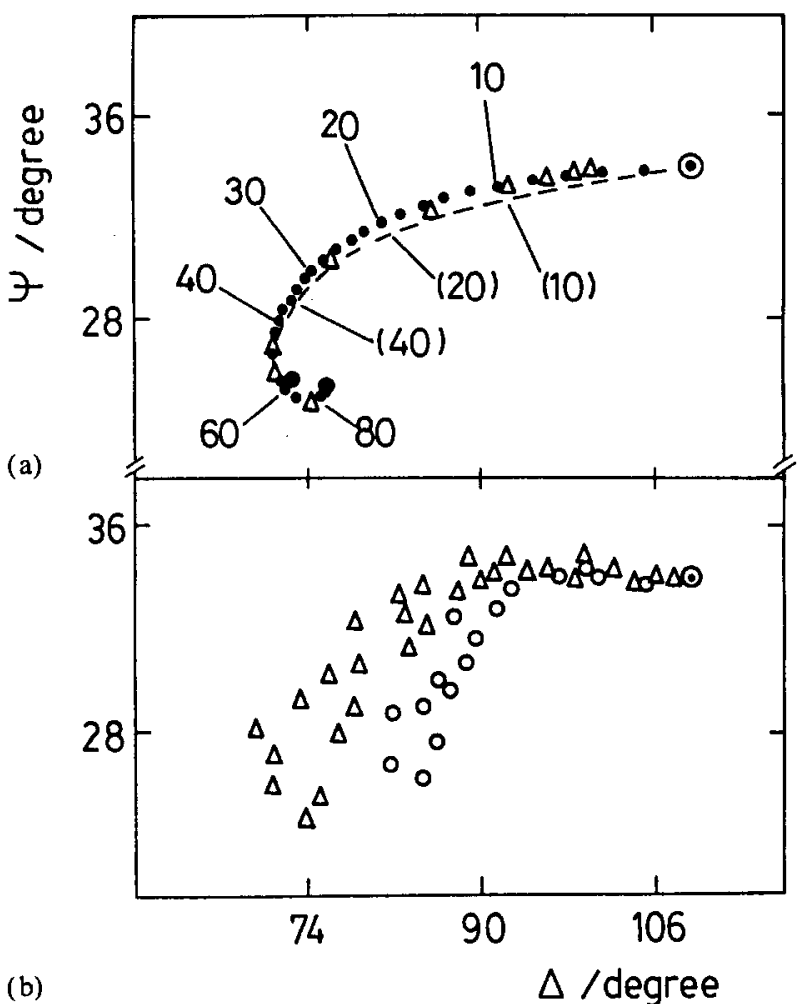

Fig. 3. Ellipsometric data obtained at $546 \mathrm{~nm}$ for EDPtE produced from HPtOL electroreduction. (a) Experimental data obtained at $v=0.002 \mathrm{~V} \mathrm{~s}^{-1}(\Delta)$, calculated data for an isotropic film $(\bullet)$ and calculated data for an anisotropic uniaxial film $(O)$. The numbers indicate the average thickness in nanometres. (b) Data from different runs at $v=0.002 \mathrm{~V} \mathrm{~s}^{-1}(\Delta)$ and $v=0.1 \mathrm{~V} \mathrm{~s}^{-1}(O)$ calculated for an isotropic film.

broken curve corresponds to the fitted theoretical curve for an isotropic homogeneous metal layer with the refractive index $n=1.865-1.733 \mathrm{i}$. A better fit is obtained for a uniaxial anisotropic film with $n_{\mathrm{p}}=1.607-$ $3.548 \mathrm{i}, n_{\mathrm{s}}=2.158-1.747 \mathrm{i}$ (full circles), where $n_{\mathrm{p}}$ and $n_{\mathrm{s}}$ are the refractive indices in the directions parallel $(\mathrm{p})$

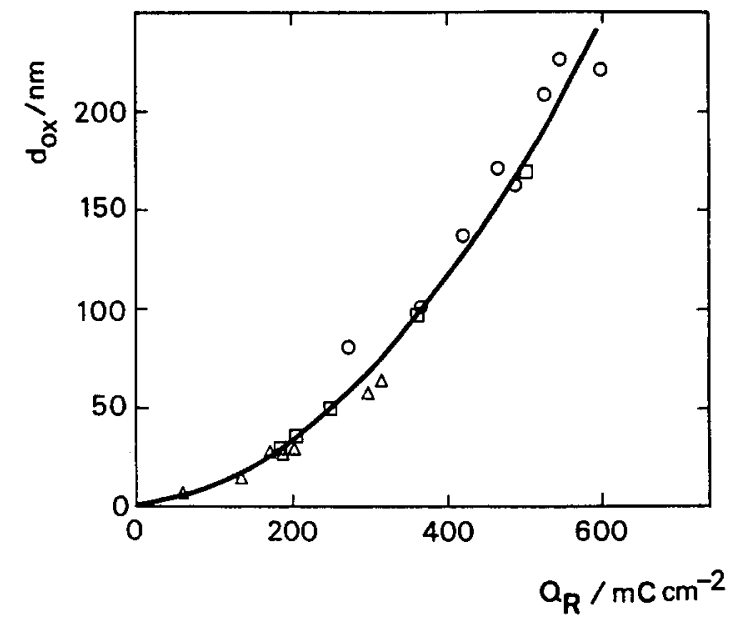

Fig. 4. Plot of $d_{\mathrm{ox}}$ vs. $Q_{\mathrm{R}}$ for different $d_{\mathrm{ox}}$.

and perpendicular ( $\mathrm{s}$ ) to the incidence plane. A trend to higher values of $n$ and $k$ at higher electroreduction rates can be observed (Table 1).

The $n v s$. $\lambda$ plots exhibit a maximum at about $550 \mathrm{~nm}$, a spectral region where the electroreflectance spectrum of the EDPtE shows a specific broad peak [23]. The dependence of the HPtOL and EDPtE thicknesses on $Q_{R}$ are depicted in Figs. 4 and 5, respectively.

\section{Discussion}

\subsection{The probable composition of the hydrous $P t$ oxide layers}

Anodic Pt oxide layers contain variable amounts of $\mathrm{H}_{2} \mathrm{O}$ depending on the preparation conditions $[6,12$, 24]. The stoichiometry of the HPtOL can be expressed as $\mathrm{PtO}_{2} \cdot p \mathrm{H}_{2} \mathrm{O}$, where $p$ is the number of moles of $\mathrm{H}_{2} \mathrm{O}$ per mole $\mathrm{PtO}_{2}$. From either the $n$ vs. $q_{\mathrm{H}_{2} \mathrm{O}}$ (or $q_{\mathrm{PtO}_{2}}$, as $q_{\mathrm{H}_{2} \mathrm{O}}=1-q_{\mathrm{PtO}_{2}}$ ) or the $k$ vs. $q_{\mathrm{H}_{2} \mathrm{O}}$ (or $q_{\mathrm{PtO}_{2}}$ ) plots,

TABLE 1. Average optical parameters derived for electrodispersed Pt electrodes: comparison with bulk Pt data

\begin{tabular}{|c|c|c|c|c|c|c|c|c|c|c|}
\hline \multirow{4}{*}{$\begin{array}{l}\lambda \\
(\mathrm{nm})\end{array}$} & \multicolumn{8}{|l|}{ EDPtL } & \multicolumn{2}{|l|}{ Pt (bulk) } \\
\hline & \multicolumn{4}{|c|}{ Scan rate of $0.002 \mathrm{~V} \mathrm{~s}^{-1}$ (case 1) } & \multicolumn{4}{|c|}{ Scan rate of $0.100 \mathrm{~V} \mathrm{~s}^{-1}$ (case 2) } & \multirow[t]{3}{*}{$n$} & \multirow[t]{3}{*}{$k$} \\
\hline & \multicolumn{2}{|c|}{$\begin{array}{l}d=1-50 \mathrm{~nm} \\
q=58 \pm 5 \text { vol. } \% \text { metal }\end{array}$} & \multicolumn{2}{|c|}{$\begin{array}{l}d=20-50 \mathrm{~nm} \\
q=54 \pm 5 \mathrm{vol} \% \text { metal }\end{array}$} & \multicolumn{2}{|c|}{$\begin{array}{l}d=1-50 \mathrm{~nm} \\
q=62 \pm 5 \text { vol. } \% \text { metal }\end{array}$} & \multicolumn{2}{|c|}{$\begin{array}{l}d=20-50 \mathrm{~nm} \\
q=59 \pm 5 \text { vol.\% metal }\end{array}$} & & \\
\hline & $n$ & $k$ & $n$ & $k$ & $n$ & $k$ & $n$ & $k$ & & \\
\hline 405 & $1.39 \pm 0.09$ & $1.74 \pm 0.07$ & $1.43 \pm 0.09$ & $1.73 \pm 0.07$ & $1.61 \pm 0.09$ & $1.96 \pm 0.07$ & $1.64 \pm 0.09$ & $1.97 \pm 0.07$ & $1.467 \pm 0.003$ & $3.003 \pm 0.005$ \\
\hline 450 & 1.50 & 1.82 & 1.55 & $1.80^{-\infty .00}$ & $1.73^{-1.03}$ & 2.07 & 1.77 & 2.08 & 1.613 & 3.272 \\
\hline 492 & 1.54 & 1.91 & 1.59 & 1.89 & 1.79 & 2.17 & 1.84 & 2.17 & 1.691 & 3.540 \\
\hline 546 & 1.57 & 2.05 & 1.63 & 2.01 & 1.86 & 2.31 & 1.92 & 2.29 & 1.797 & 3.917 \\
\hline 580 & 1.49 & 2.20 & 1.55 & 2.14 & 1.82 & 2.49 & 1.88 & 2.44 & 1.759 & 4.267 \\
\hline 671 & 1.66 & 2.46 & 1.71 & 2.40 & 2.07 & 2.71 & 2.13 & 2.66 & 2.122 & 4.725 \\
\hline
\end{tabular}




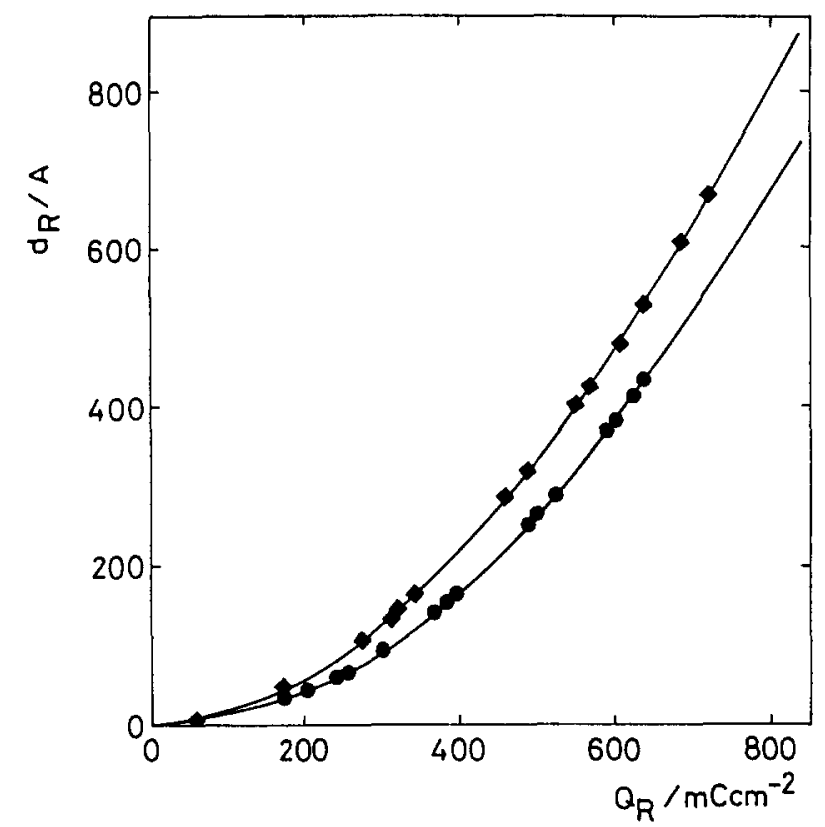

Fig. 5. $d_{\mathrm{R}}$ vs. $Q_{\mathrm{R}}$ plot for EDPtEs for two electroreduction conditions: $\bullet, v=2 \mathrm{mV} \mathrm{s}^{-1} ; \bullet, v=100 \mathrm{mV} \mathrm{s}^{-1}$.

where $q$ is the fractional molar $\mathrm{H}_{2} \mathrm{O}$-to- $\mathrm{PtO}_{2}$ volume ratio; a second estimation of the latter can also be made through the Maxwell Garnett [25] theory (MGT) [26] by assuming that the HPtOLs can be described in terms of a composite material. In this case, for $q_{\mathrm{PtO}_{2}}=1$ and knowing the composition of $\beta-\mathrm{PtO}_{2}$, then values $n=2.44$ and $k=0.08$ at $\lambda=546 \mathrm{~nm}$ were chosen [27]. Then, from the experimental value $n=1.59$, we find that $q_{\mathrm{H}_{2} \mathrm{O}}=0.77 \quad\left(q_{\mathrm{PtO}_{2}}=0.23\right)$, i.e. $n_{\mathrm{H}_{2} \mathrm{O}} / n_{\mathrm{PtO}_{2}}=4.1$. The fitting procedure applied to data obtained at different thicknesses [28] shows small decreases in $n$ and $k$ for increasing thicknesses corresponding to a change in $q_{\mathrm{H}_{2} \mathrm{O}} \approx 0.04$.

Analogous results can be obtained from the $d_{\mathrm{ox}} v s$. $Q_{\mathrm{R}}$ plot. Accordingly, by taking the specific gravity of $\mathrm{PtO}_{2}$ as $10.2 \mathrm{~g} \mathrm{~cm}^{-3}$, the volume of water can be obtained. From these results it was concluded that for $d_{\mathrm{ox}} \longrightarrow 0$, the composition of the HPtOL approaches that of the anhydrous $\mathrm{PtO}_{2}$ layer whereas, for $Q_{\mathrm{R}}>$ $300 \mathrm{mC} \mathrm{cm}^{-2}, p \longrightarrow 4$, the composition of the HPtOL tends to be $\mathrm{Pt}(\mathrm{OH})_{4} \cdot 2 \mathrm{H}_{2} \mathrm{O}$.

Therefore the present results show that the ellipsometric response of HPtOLs differs considerably from the response of other Pt anodic layers formed on Pt in acid when the potential is anodic to $0.95 \mathrm{~V}[29,30]$, as in the former case the $\mathrm{H}_{2} \mathrm{O}$ content becomes larger than that assigned to chemically prepared $\mathrm{Pt}$ oxide layers such as $\mathrm{PtO} \cdot \mathrm{H}_{2} \mathrm{O}$ [31-33].

\subsection{The electrodispersed Pt electrodes}

Considering that the light beam domain of the rough surface is equivalent to a homogeneous layer on a flat surface for the reflection of light $[18,25,26,34,35]$, the EDPtEs can be described as a single composite layer involving a population of metal grains and voids under certain geometric arrangements. Accordingly, the dielectric and transport properties of the EDPtE composite layer can be approximated in a generalized way from either the MGT or the effective-medium theory (EMT).

The values of $n$ and $k$ for EDPtE, i.e. $n_{\mathrm{eff}}$ and $k_{\mathrm{eff}}$ respectively, as a function of the metal-grain-to-void volume ratio $q$ were calculated from both the MGT and the EMT, by taking the values of $n$ and $k$ of bulk Pt in the $400-700 \mathrm{~nm}$ range and assuming that the voids filled up with the electrolyte solution. The MGT was applied to both a dispersion of $\mathrm{Pt}$ in $\mathrm{H}_{2} \mathrm{O}$, and a dispersion of $\mathrm{H}_{2} \mathrm{O}$ in Pt. Further, the values of $n_{\text {eff }}$ and $k_{\text {eff }}$ plotted against $q$ can be compared with the experimental $n$ and $k$ values resulting from the $\Delta v s$. $\Psi$ relations for the EDPtEs obtained under different conditions.

\subsubsection{The electrodispersed Pt electrodes formed at $0.002 \mathrm{Vs}^{-1}$}

Different geometric models can be used to describe the rough metal surface such as square ridge, brushlike, triangular ridge and regular pyramid models [18]. Geometric models such as those involving either square ridges or brush-like or parallel columnar structures imply $z$-independent $q$ values.

Both the MGT and the EMT were used to determine the influence of surface geometry on the $\Delta v s . \Psi$ plots. The $\Delta v s . \Psi$ plots resulting from the EMT for values of $n$ and $k$ for bulk $\mathrm{Pt}$ and $\mathrm{H}_{2} \mathrm{O}$ [36-38] and $0.5<q<0.7$ exhibit the same type of curvature as the experimental $\Delta v s$. $\Psi$ plots. This comparison favours a description of the EDPtE structure as a $z$-independent composite layer fitting the predictions of the EMT for $q=$ $0.58 \pm 0.05$ (Table 1). The EMT for $0.15<q_{\mathrm{Pt}}<0.70$ predicts an increase in the value of $k$ and a decrease in the value of $n$ as $q_{\mathrm{pt}}$ increases. The same value of $q$ can be derived from either $n$ or $k$ as expected from the coherence of the model. Therefore the geometric structure of the EDPtEs in the 1-50 nm average thickness range resulting from the electroreduction at $0.002 \mathrm{~V} \mathrm{~s}^{-1}$ can approach that of a composite Pt layer consisting of $(58 \pm 5) \%$ metal grains and $(42 \pm 5) \%$ voids filled up with the electrolyte solution. These values are close to 0.5 , as concluded earlier from scanning tunnelling microscopy image processing [14].

\subsubsection{The electrodispersed $P t$ electrodes obtained} at $0.1 \mathrm{Vs}^{-1}$

The effective values of $n$ and $k$ for EDPtEs produced at $0.1 \mathrm{~V} \mathrm{~s}^{-1}$ can be explained as produced by a metalto-voids ratio of about $60-70 \%$ by using $n$ and $k$ values of bulk Pt [36-39] and $1.33<n<1.76$ for the elec- 
trolyte solution. In this case the upper limiting value of $n$ approaches the $n$ value of ice [36, 38].

These results suggest that the EDPtE structure resulting at $0.1 \mathrm{~V} \mathrm{~s}^{-1}$ involves grains larger than those found at $0.002 \mathrm{~V} \mathrm{~s}^{-1}$. This type of deposit has been found for EDPtEs after aging for several hours in the electrolyte solution [14-17].

\section{Conclusions}

(i) Ellipsometry data on the rough surfaces of HPtOLs and EDPtEs are reported for the first time.

(ii) The values of $n$ and $k$ for HPtOLs correlate to those calculated for a composite material consisting of $\mathrm{PtO}_{2}$ and $\mathrm{H}_{2} \mathrm{O}$.

(iii) The probable stoichiometry of the HPtOLs derived from ellipsometry can be represented as $\mathrm{PtO}_{2}$. $p \mathrm{H}_{2} \mathrm{O}$, where the value of $p$ lies between 2 and 4 . The $\mathrm{H}_{2} \mathrm{O}$ content in the HPtOLs increases in going from the inner to the outer portion of the oxide layer.

(iv) The EDPtE ellipsometric behaviour can be approached in terms of a composite structure described by the EMT with a metal-to-void ratio of between 0.3 and 0.6 .

(v) At EDPtEs the metal-to-void ratio becomes independent of the direction perpendicular to the electrode surface, in agreement with the brush-like structure concluded from scanning tunnelling microscope image processing [14-17] and Monte Carlo simulation of the corresponding growth processes $[40,41]$.

\section{Acknowledgment}

This work was supported by the Consejo Nacional de Investigaciones Científicas y Técnicas.

\section{References}

1 A. C. Chialvo, W. E. Triaca and A. J. Arvia, J. Electroanal. Chem., 146 (1983) 93.

2 A. Visintin, J. C. Canullo, W. E. Triaca and A. J. Arvia, J. Electroanal. Chem., 221 (1987) 239; 239 (1988) 67.

3 L. D. Burke, M. B. C. Roche and W. A. O'Leary, J. Appl. Electrochem., 18 (1988) 781.

4 K. Kinoshita, in J. O'M. Bockris, B. E. Conway and R. E. White (eds.), Modern Aspects of Electrochemistry, Vol. 14, Plenum, New York, 1982, p. 559.

5 D. Gilroy and B. E. Conway, Can. J. Chem., 46 (1968) 875.

6 M. Peuckert, Electrochim. Acta, 29 (1984) 1315.

7 S. Shibata and M. P. Sumino, Electrochim. Acta, 17 (1971) 2215.
8 A. J. Arvia, R. C. Salvarezza and W. E. Triaca, Electrochim. Acta, 34 (1989) 1057.

9 D. James, J. Electrochem. Soc., 116 (1969) 1681.

10 J. S. Hammond and N. Winograd, J. Electroanal. Chem., 31 (197!) 29.

11 A. Reddy, M. Genshaw and J. O'M. Bockris, J. Electroanal. Chem., 8 (1964) 406.

12 M. Peuckert and A. P. Bonzel, Surf. Sci., 145 (1984) 239.

13 E. Rach and J. Heitbaum, Electrochim. Acta, 31 (1986) 477.

14 L. Vásquez, J. Gómez, A. M. Baró, N. García, M. L. Marcos, J. González Velasco, J. M. Vara, A. J. Arvia, J. Presa and M. Aguilar, J. Am. Chem. Soc., 109 (1987) 1730.

15 J. Gómez, L. Vásquez, A. M. Baró, C. Alonso, E. González, J. González-Velasco and A. J. Arvia, J. Electroanal. Chem., 240 (1988) 77.

16 J. Gómez, L. Vásquez, A. M. Baró, C. L. Perdriel and A. J. Arvia, Electrochim. Acta, 34 (1989) 619.

17 L. Vásquez, A. Bartolomé, A. M. Baró, C. Alonso, R. C. Salvarezza and A. J. Arvia, Surf. Sci., 215 (1989) 171.

18 C. A. Fenstermaker and F. L. McCrakin, Surf. Sci., 16(1969) 85.

19 T. V. Vorburger and K. C. Ludema, Appl. Opt., 19 (1980) 561.

20 D. E. Aspnes, in E. D. Palik (ed.), Handbook of Optical Constants of Solids, Academic Press, Orlando, FL, 1985, Chapter 5, p. 89.

21 D. den Engelsen, J. Opt. Soc. Am., $6 I$ (1971) 460.

22 J. Newman, J. Electrochem. Soc., 113(1966) 501; 113(1966) 1235.

23 R. O. Lezna, N. R. de Tacconi, C. L. Perdriel and A. J. Arvia, in S. Srinivasan, S. Wagner and H. Wroblowa (eds.), Prof. Conf. on Electrode Materials and Processes for Energy Conversion and Storage, in Electrochem. Soc. Proc., 87-12 (1987) 31.

24 R. Wood, in A. J. Bard (ed.), Electroanalytical Chemistry, Vol. 9, Arnold Press, London, 1977, p. 2.

25 J. C. Maxwell Garnett, Phil. Trans. R. Soc. London, 203 (1904) 385; 205 (1906) 237.

26 D. E. Aspnes, Thin Solid Films, 89 (1982) 249.

$27 \mathrm{Yu}$. Ya. Ninnikov, V. A. Shepekin and V. I. Veselovskii, Elektrokhimiya, 9 (1973) 649.

28 J. O. Zerbino, W. J. Plieth and G. Kossmehl, J. Appl. Electrochem., 21 (1991) 935.

29 A. K. N. Reddy, M. A. Genshaw and J. O'M. Bockris, J. Chem. Phys., 48 (1968) 671.

30 S. Gottesfeld, G. Maia, J. B. Floriano, G. Tremiliosi-Filho, E. A. Ticianelli and E. R. Gonzalez, J. Electrochem. Soc., 128 (1991) 3219.

31 Yu. Ya Ninnikov, V. A. Shepelin and V. I. Veselovskii, Elektrokhimiya, 9 (1973) 552.

32 W. Vinlier, Optik, 26 (1968) 402.

33 J. Horkans, B. D. Cahan and E. Yeager, Surf. Sci., 46 (1974) 1.

34 J. I. Gittleman and B. Abeles, Phys. Rev. B, 15 (1977) 3273.

35 C. G. Granqvist and O. Hunderi, Phys. Rev. B, 18 (1978) 2897.

36 M. A. Barret and R. Parsons, Proc. Symp. Faraday Soc., Vol. 4, The Faraday Society, London, 1970, p. 72.

37 F. Franks (ed.), Water, A Comprehensive Treatise, Vol. 2, Plenum, New York, 1973, p. 183.

38 K. Schäfer and E. Lax (eds.), Landolt-Börnstein, Zahlenwerte und Funktionen aus Physik, Chemie, Astronomie, Technik, Vol. 2, Part B, Springer, Berlin, 1960.

39 G. A. Nicklason, C. G. Granquist and O. Hunderi, Appl. Opt., 20 (1981) 26.

40 E. V. Albano, H. O. Martin, R. C. Salvarezza, M. E. Vela and A. J. Arvia, J. Electrochem. Soc., 137 (1990) 117.

41 R. C. Salvarezza, C. Alonso, J. M. Vara, E. V. Albano, H. O. Martin and A. J. Arvia, Phys. Rev. B, 41 (1990) 12502. 